\title{
Confabulation: A Beginner's Guide for legal professionals
}

\author{
Jerrod Brown ${ }^{1,2,3}$, Cody Charette ${ }^{4}$, Deb Huntley ${ }^{1}$, Anthony P Wartnik ${ }^{1}$, Cameron R Wiley ${ }^{5}$ Janina Cich $^{1,3}$, Stephen Morgan ${ }^{1}$ and Kimberly D \\ Dodson $^{6}$ \\ ${ }^{1}$ Concordia University, St. Paul, MN, USA \\ ${ }^{2}$ Pathways Counseling Center, St. Paul, MN, USA \\ ${ }^{3}$ The American Institute for the Advancement of Forensic Studies, St. Paul, MN, USA \\ ${ }^{4}$ Alliant International University \\ ${ }^{5}$ North Carolina Central University, Durham, NC USA \\ ${ }^{6}$ University of Houston - Clear Lake, Houston, TX USA
}

\begin{abstract}
Confabulation can be defined as the unintentional creation of a false or inaccurate memory to compensate for memory gaps or deficits. Although some similarities may exist, the phenomenon of confabulation is distinguishable from other issues like suggestibility, malingering, and delusions. The possibility of confabulation is particularly pernicious in criminal justice settings. Here, self-reported memories play an integral role in the confessions and testimony of suspects, defendants, victims, and eyewitnesses. To raise awareness of this possibility, and protect against its consequences, this article reviews warning signs and risk factors for confabulation, tips on how to communicate with and treat individuals who may be confabulating, and recent research in the area of confabulation. In short, this serves as an introduction to confabulation for legal professionals.
\end{abstract}

\section{Confabulation: An introduction}

Confabulation is the act of providing inaccurate information without the intention to deceive [1,2]. The basis of this information can take several forms including being the result of gaps in memory, distortions of actual autobiographical recollections, problems retrieving factual information, or the fabrication of memories with no basis in reality. In this context, autobiographical recollections consist of memories of personally experienced events [3-5]. Similarly, problems retrieving factual information in this context consists of facts not related to the episodes of one's own life but a general knowledge of the world $[2,6,7]$. This phenomenon can be the result of brain damage or other cognitive deficits that involve a host of memory errors ranging from small distortions of actual experiences to the creation of novel and bizarre memories that are not plausible in the real world. Detection is made more difficult because individuals who confabulate believe that what they are saying is accurate, true, and correct. Confabulation is a challenging and often confusing phenomenon to understand because it has an uncertain etiology and an array of forms in which it presents. Part of the confusion lies in the fact that confabulation has multiple definitions, types, and forms.

There are two main types of confabulation: spontaneous and provoked [8]. Spontaneous confabulations are unprompted attempts at filling in gaps in memory. Such confabulations are relatively rare, manifesting mainly in cases of dementia and Alzheimer's disease. Spontaneous confabulation is believed to be an interaction between frontal lobe pathology and organic amnesia [9]. Provoked confabulations occur in response to a prompt, or an external cue, and may represent a normal response to a faulty memory [10]. These types of confabulation can become apparent during memory tests, interviews, or under cross-examination.
Confabulation most commonly takes either verbal or behavioral forms. Verbal confabulation occurs when someone states a false memory. In contrast, behavioral confabulation occurs when someone physically acts on his or her own false memory [11-13]. Whereas confabulation can arise in individuals with no identified cognitive or psychiatric conditions, it often associated with an extensive range of neurocognitive and psychiatric disorders. Disorders associated with confabulation include traumatic brain injury (TBI), schizophrenia, post-traumatic stress disorder (PTSD), Wernicke-Korsakoff syndrome (WKS), fetal alcohol spectrum disorder (FASD), frontotemporal dementia, and Alzheimer's disease [14-19]. Confabulation has also been documented in individuals with no apparent brain impairment or disorder or cognitive limitation [18].

The prevalence rate of confabulation in both general and criminal justice-involved populations is currently unknown. Although confabulation may be an unfamiliar concept to legal professionals, it has a disproportionate significance within the criminal justice and civil legal systems. Throughout their careers, it is likely that legal professionals will encounter at least one individual, and probably multiple individuals who confabulate. As such, legal professionals are encouraged to become familiar with this memory phenomenon.

Correspondence to: Jerrod Brown, 1919 University Ave. W. Suite 6 St. Paul MN, 55104, USA, E-mail: jerrod01234brown@live.com

Keywords: Confabulation, criminal justice, court, legal, memory

Received: August 20, 2017; Accepted: September 27, 2017; Published: September 30, 2017 


\section{Criminal justice system implications}

Despite being a largely unfamiliar topic to legal professionals, confabulation can have a detrimental impact on individuals involved in the criminal justice system as well as the integrity of the judicial process itself $[14,15,20,21]$. In legal settings, individuals prone to confabulation may be at an increased risk to provide inaccurate statements while being questioned by law enforcement officers or attorneys. For example, some individuals who confabulate may make false confessions they believe to be completely accurate. A bizarre and tragic account of the depth, breadth, and severity of this phenomenon was recently reported in an article in The New Yorker magazine. In the article, the author reports on the false, yet firmly believed confessions of six individuals to the sexual assault and murder of a woman. After a trial and guilty verdict for all six, a DNA evidence later exonerated them. Even after the exoneration each truly believed they had committed the crime [22]. Given that many legal processes strongly rely on the accounts of a defendant or witness, confabulation is highly damaging to a criminal defendant at trial. If present, confabulation can taint confessions, field interviews, eyewitness testimonies, jury verdicts, and adversely affect sentencing outcomes. This is particularly pertinent during stressful situations such as interrogations, where the use of deception, misinformation, and manipulation are all legal and common [20,23,24]. A confabulating individual may relay completely false or partially inaccurate witness accounts that may lead to the wrongful prosecution or conviction of others. In addition, a confabulating individual may unknowingly provide a false alibi for someone, and a guilty person walks free. However, if prosecutors discover a person lied under oath, that person may be charged with perjury even though he or she had no intention to lie. Confabulation can also interfere with the defendant's ability to assist counsel in his or her defense, up to and including rendering the defendant incompetent to stand trial $[16,25,26]$.

Confabulation also affects performance on tasks requiring memory, including responding during interrogations, testifying in court, and participating in court-ordered forensic assessments [2527]. Additionally, it may confer a vulnerability to suggestibility, which exacerbates the issues described above when certain suggestive and closed-ended questions used in interview techniques are utilized (e.g., disorders including amenesia). To protect against the potential impact of confabulation on the criminal justice process, legal professionals should remain skeptical of the accounts made by individuals with a history of confabulation and associated risk factors. Verifying the reported information with collateral evidence from third-party witnesses or corroborating physical evidence can then alleviate the skepticism. In some cases, confabulation can even contribute to continued involvement in the criminal justice system if it is not recognized early, as individuals inadvertently continue to provide objectively false information in an attempt to please other people. As such, legal professionals should be familiar with confabulation to provide or refer the client to appropriate services. With all of this in mind, the remainder of this article reviews some important considerations, presented in alphabetical order, about confabulation that all legal professionals should know.

\section{Points and considerations}

\section{Accurate recall}

Suffering from confabulation may make it difficult for an individual to navigate the legal process. The ability to accurately recall events is an integral component of this multifaceted and often complex process. From police interrogations to testifying in court, a wide range of legal activities rely on complete, honest, and accurate recollection [25$27,29]$. The integrity of these steps is compromised when an individual who confabulates goes undetected but is still required to go through the aforementioned legal procedures. Further complications arise if executive functioning and memory-related impairments related to additional co-morbid mental disorders affect the individual.

\section{Collateral sources}

If confabulation is suspected, or subsequently confirmed, it is critical to be wary of the individual's accounts and recall. When determining the accuracy of a client's self-reported accounts, legal professionals may need to use collateral sources as an alternative way to obtain accurate information or to determine the veracity of client's recollections. Interviewing close family members who can confirm the individual's past proclivities and behaviors, as well as friends who can attest to their personality and affect, can provide verified confirmation. Additionally, official documents like medical and criminal justice records, help paint a more complete and accurate picture of the both situation and the afflicted individual $[14,30]$.

\section{Continuing education training}

Few advanced training and education options geared toward identifying and understanding confabulation exist for legal professionals. Education and training programs that focus on the legal and forensic aspects of confabulation are desperately needed. Specifically, being able to identify potential symptoms of confabulation and seeking the proper assistance for affected individuals is crucial. Through advanced training and education, these professionals can improve their ability to identify, manage, and assist clients who confabulate.

\section{Delusions}

It is essential that delusions be distinguished from confabulation. To the untrained observer, delusions and confabulation may appear to be similar afflictions [31]. However, a major difference lies in the strength of their commitment to the belief or memory. Delusions are defined as the firm, false beliefs that can be maintained even in the face of contradicting arguments or evidence [32]. Conversely, confabulations are defined as inaccurate memories and can be altered in the presence of high pressure or convincing alternatives.

\section{Documentation}

If legal professionals suspect that confabulation is present, they must document it in the case file. Attempts must then be made to obtain confirmation from reliable secondary sources as described in collateral sources above [30]. If a diagnosis is confirmed, all subsequent steps of the legal process must be tailored to the unique circumstances confabulation presents. It is critically important to effectively challenge false confessions in court, where the truthful nature of confabulated confessions can be more closely scrutinized.

\section{Effective intervention}

Effective interventions for confabulation may require the establishment and maintenance of working relationships with other professionals in relevant fields, including mental health providers who possess experience in dealing with confabulation in forensic settings. Confabulation, by its very nature, necessitates enlisting a multidisciplinary team of professionals to increase the likelihood of success for both the individual and their case [33]. 


\section{Explore}

Exploration of how confabulation may have affected individuals in their personal and professional life is paramount $[15,16,21,30,34]$. Are individuals aware that their life has been affected by confabulation? How has confabulation impacted their relationship with family, friends, or professional service providers as described by the afflicted individual? The answers to these questions are essential to helping the client, or patient, and must be verified by secondary sources. It is also important for legal professionals to explore the impact confabulation has had on the individual's overall legal process so proper adjustments can be established.

\section{Identification issues}

The identification of confabulation is extremely difficult to the untrained observer. Identification is complicated by the fact that individuals afflicted by confabulation are unaware, or lack insight, which they suffer from this memory phenomenon $[35,36]$. Furthermore, some of the symptoms for confabulation can be attributed to a host of other disorders, both cognitive or behavioral, or are mistaken as delusional behavior or malingering. Confabulation can vary wildly by case, which increases the difficulty of identification, assessment, and appropriate intervention.

\section{Lying}

Confabulation is distinct from willful lying. By definition, individuals who suffer from confabulation are not aware that their memory is inaccurate and are not trying to intentionally deceive anyone. Conscious lying is generally willful and done for the purpose of deception. The individual engaged in lying is consciously aware that the information provided is not accurate $[25,26]$.

\section{Inaccurate self-reports}

The screening and assessment process of these clients can be difficult given that confabulation could render a client's self-report as unintentionally inaccurate. The false nature of these reports may be masked by the client's perceived normal appearance and apparent conviction as they provide their accounts $[21,25,30,34]$. Unfortunately, the consequences of not effectively addressing this issue often result in inaccurate diagnoses, inappropriate treatment, and improper sentencing outcomes. In extreme circumstances, confabulation may be a factor in cases involving false arrest, wrongful prosecution, or conviction of an innocent person $[14,16,30]$.

\section{Interviews and interrogation}

Stress and anxiety can lead to or exacerbate confabulation. Unfortunately, these factors are common throughout the interactions that take place during the judicial process. Interviews or interrogations that are argumentative, hostile, insistent, or make suggestions to an individual through the use of leading questions may increase the risk of confabulating memories $[37,38]$. To increase the comfort level of the interviewee, it is advisable to adjust the tone of the interrogation or interview to decrease the potential for stress and anxiety. Additionally, open-ended questions provide the affected individual with more freedom in their answers. Closed-ended questions place increasing pressure on the individual to give a certain answer from a short list of possibilities, which often results in an increased chance for confabulation in order to fit the narrative being presented and thereby please the interviewer $[14,16]$.

\section{Malingering}

Confabulation is the creation of false memories in the absence of intentional deception. In this phenomenon, the individual's sincere conviction of the absolute veracity of the false memory distinguishes it from malingering, or the intentional telling of untruths. It is not "lying" in the conventional sense of the word. This is an important point to emphasize because untrained professionals may misinterpret confabulation as a malicious attempt to deceive rather than the product of neuropsychological deficits. Those who confabulate may simply be trying to ease the stress of their current situation by appeasing the interviewer, rather than purposefully attempting to subvert or aggravate it. Whether distorted memories of an actual event or the creation of an imagined one, confabulation should not be confused with intentional lying, or malingering, for personal gain [15,25,26].

\section{Memory confidence}

The accuracy of memory does not increase as a function of confidence in one's own memory ability. This issue is particularly salient when confabulation is suspected or confirmed to be present [39]. People, including legal professionals and jurors, are more likely to believe a memory is true if the person appears confident in that memory. The convincing nature of an individual's confabulations may establish the foundation for faulty decisions by legal and mental health professionals, which can have significant negative consequences long into the future.

\section{Memory problems}

Individuals who confabulate may suffer from short- and long-term memory loss. In some instances, these individuals may be unable to recall important details from recent events $[39,40]$. This is a skill that is critical to the accuracy of interrogations and testimonies. In other circumstances, confabulations involving autobiographical information can lead to inaccurate assessments and diagnoses in forensic settings. These deficits may be more severe among individuals with co-occurring neurocognitive or neuropsychiatric disorders [13].

\section{Misdiagnosis}

Since confabulation can result in an inaccurate diagnosis, legal professionals should reconsider the appropriateness of any previous diagnoses that may affect or account for the presentation of confabulation. This reconsideration may include co-morbid disorders such as FASD, TBI, and bipolar disorder among others [14,17,4143]. The challenge for the professional is determining whether the confabulation is a result of some other phenomenon or independent of external circumstances. This consideration is especially important when the court orders an evaluation of competency to stand trial.

\section{Misinterpretation of intent}

Despite the facade of confidence and accuracy, individuals may confabulate entirely false memories of imagined details or events $[2,32,36]$. It is important to note that in some instances, confabulation can be based on partially true information grounded in a kernel of truth. Confabulation by definition has no malicious component. The presentation of false information is genuine and unintentional. If these characteristics are not well understood, legal professionals may mistake the phenomenon as a means to escape punishment. In time, the professional may become resentful or frustrated with the individual, which can negatively affect their subsequent treatment and the quality of the legal services provided. As such, the recognition of 
confabulation remains incredibly difficult but extremely important for legal professionals.

\section{Psychological testing}

The presence of confabulation may necessitate more advanced neurological and psychological screening compared to typical cases where such measures would not be necessary $[15,21,34]$. When confabulation is suspected, legal professionals should consider referral to a qualified mental health professional to ensure appropriate psychological and neurological testing to establish definitive confirmation. Expert testimony in court also may be required to educate the judge, jury, and other attorneys about the features of confabulation and its detrimental impact on the criminal justice process. That testimony, in large part, will be based on data from the psychological testing conducted by the multidisciplinary team or a clinician.

\section{Suggestibility}

Individuals who suffer from confabulation may also be prone to suggestibility [20,29]. Specifically, these individuals may be likely to adopt the statements or views of others when asked the same question repeatedly or when they are given negative feedback. This is commonplace during police interrogations and cross-examination by attorneys at trial, so it is important to create a calm, low-pressure environment and avoid using suggestive or leading questions and statements. Permitting for an independent recall of information will likely reduce their propensity of integrating outside influences, details, or confabulation of their narrative $[14,16]$.

\section{Understand}

Legal professionals should understand the potential consequences and outcomes of confabulation, especially when there have been multiple verifiable instances from an individual. Confabulation can be emotionally stressful for both the individual and the people that they encounter. This is especially true for those that are directly involved with their case. By having an awareness of and greater understanding regarding the complexities of confabulation and its impact on the various stages of the trial process, legal professionals will be better prepared mentally and emotionally to assist affected clients.

\section{Suggestions for further research}

Confabulation is in desperate need of systematic and sophisticated research. Foremost, research has the potential to help clarify what confabulation is and how it manifests itself. This information is of great value to professionals working in mental health and criminal justice settings. One viable option of accomplishing this goal is the administration of surveys to different groups of professionals. For example, surveys of legal professionals like attorneys and judges can help crystallize what these professionals know and how they think about confabulation in their respective fields. Similar surveys for forensic evaluators are also ideal, as this group is often tasked with both evaluating a client and later testifying about them before the court. Beyond those that play a role in trials, it is also essential to understand what corrections professionals, such as parole officers and correctional officers, and mental health professionals, such as substance use treatment providers, know about confabulation. Last but not least, surveys exploring the insights of family members, caregivers, and peers may be extremely beneficial to the field. A recurring theme in surveys to all of these groups must be an effort to improve understanding of how confabulation impacts an individual's ability to navigate the legal system. This is especially important for those going through competency to stand trial evaluations or those having to make different legal decisions such as whether to request a jury trial or waive certain individual rights. Responses to such questions across these groups have the potential to help identify ways to improve how services are provided to criminal justice-involved individuals who confabulate or are at an increased risk to confabulate. If the information presented above receives due consideration, there will be several opportunities to improve short- and long-term outcomes for these individuals.

\section{Conclusion}

The negative effects of confabulation on the criminal justice system are many and varied. Legal professionals are likely to encounter individuals who confabulate at some point during their careers. To minimize the consequences of confabulation, these professionals should become more familiar with the characteristics of the phenomenon and its potential ramifications on the various stages of the judicial process. Familiarizing themselves with the current published research literature can facilitate a better understanding of confabulation. In so doing, appropriate approaches and intervention strategies can be applied. These strategies can dramatically increase the likelihood of long-term success for both the affected individual and the overall outcome of his or her criminal case. Advanced training, education, and consultation may also be necessary when attorneys and other criminal justice personnel encounter clients who confabulate. In summary, due to the serious negative impact of confabulation on criminal-justice-involved populations, there is a genuine need for education and training programs about confabulation for all legal professionals.

\section{References}

1. Fotopoulou A (2008) False selves in neuropsychological rehabilitation: The challenge of confabulation. Neuropsychological Rehabilitation 18 (5/6): 541-565.

2. Moscovitch M (1989) Confabulation and the frontal system: Strategic versus associative retrieval in neuropsychological theories of memory. In: Roediger HL, Craik FIM (eds.) Varieties of Memory and Consciousness: Essays in the Honour of Endel Tulving (pp 133-160) Hillsdale, NJ: Lawrence Erlbaum Associates.

3. Dalla Barba G (1993) Confabulation: Knowledge and recollective experience. Cognitive Neuropsychology 10: 1-20.

4. Gilboa A, Alain C, Stuss DT, Melo B, Miller S, Moscovitch M (2006) Mechanisms of spontaneous confabulations: A strategic retrieval account. Brain 129: 1399-1414.

5. Schnider A (2003) Spontaneous confabulation and the adaptation of thought to ongoing reality. Nature Reviews Neuroscience 4: 662-671.

6. Burgess PW, Shallice T (1996) Confabulation and the control of recollection. Memory 4: 359-411. [Crossref]

7. Conway MA, Tacchi PC (1996) Motivated confabulation. Neurocase 2: 325-338.

8. Kopelman MD (1987) Two types of confabulation. J Neurol Neurosurg Psyc 50: 14821487.

9. Coltheart M, Turner M (2009) Confabulation and Delusion. In: Hirstein W (Ed.), Confabulation: Views from neuroscience, psychiatry, psychology, and philosophy (pp. 173-187) Oxford University Press.

10. Cooper JM1, Shanks MF, Venneri A (2006) Provoked confabulations in Alzheimer's disease. Neuropsychologia 44: 1697-1707. [Crossref]

11. Moscovitch M (1995) Confabulation. In: Schacter DL, Coyle JT, Fischbach JD, Mesulam MM, Sullivan LE (Eds.), Memory distortion: How minds, brains, and societies reconstruct the past (pp. 226-251) Cambridge, MA: Harvard University Press.

12. Rensen YC, Oosterman JM, van Damme JE, Griekspoor SI, Wester AJ, et al. (2015) Assessment of confabulation in patients with alcohol related cognitive disorders: The Nijmegen-Venray Confabulation List (NVCL-20) The Clinical Neuropsychologist 29: 804-823.

13. Schnider A (2008) The confabulating mind: How the brain creates reality. New York, NY: Oxford University Press.

14. Brown J (2017) Fetal alcohol spectrum disorder and confabulation: A clinical, forensic, and judicial dilemma. The Journal of Special Populations 1: 1-11. 
15. Brown J, Fordice H, Weaver J, Hesse M (2015) Wernicke-Korsakoff Syndrome and confabulation: A review for criminal justice professionals. Behavioral Health 3: 1-8.

16. Brown JM, Haun J, Zapf PA, Brown NN (2017) Fetal alcohol spectrum disorders (FASD) and competency to stand trial (CST): Suggestions for a 'best practices' approach to forensic evaluation. International Journal of Law and Psychiatry 52: 19-27.

17. Gilboa A, Moscovitch M (2002) The cognitive neuroscience of confabulation: A review and a model. In: Baddeley A, Kopelman M, Wilson B (Eds.), Handbook of Memory Disorders (2nd ed, pp. 315-342) Chichester: John Wiley.

18. Hirstein W (2005) Brain fiction: Self-deception and the riddle of confabulation. MIT Press.

19. Lindholm C (2015) Parallel realities: the interactional management of confabulation in dementia care encounters. Research on Language and Social Interaction, 48: 176-199.

20. Gudjonsson GH (2003) The psychology of interrogations and confessions: A handbook. London, UK: John Wiley \& Sons, Ltd.

21. Huntley D, Brown J, Wiley CR (2016) Confabulation and mental health: A beginner's guide. Behavioral Health 4: 1-9.

22. Aviv R (2017, June 19) Remembering the murder you didn't commit. The New Yorker.

23. 23.Gudjonsson G (2017) Memory distrust syndrome, confabulation and false confession. Cortex 87: 156-165. [Crossref]

24. Gudjonsson GH, Sigurdsson JF, Sigurdardottir AS, Steinthorsson H, Sigurdardottir VM (2014) The role of memory distrust in cases of internalised false confession. Applied Cognitive Psychology 28: 336-348.

25. Brown J, Hesse M, Rosenbloom M, Harris B, Weaver J, et al. (2015) Confabulation in Correctional Settings: An Exploratory Review. The Journal of Law Enforcement 4: 1-8

26. Brown J, Long-McGie J, Oberoi P, Wartnik A. Wresh J, et al. (2015) Confabulation: Connections between brain damage, memory, and testimony. Journal of Law Enforcement 3: 1-11

27. Smith P, Gudjonsson GH (1995) Confabulation among forensic inpatients and its relationship with memory, suggestibility, compliance, anxiety, and self-esteem. Personality and Individual Differences 19: 517-523.

28. Gudjonsson GH, Young S (2010) Does confabulation in memory predict suggestibility beyond IQ and memory? Personality and Individual Differences 49: 65-67.

29. Gudjonsson GH, Clare IC (1995) The relationship between confabulation and intellectual ability, memory, interrogative suggestibility and acquiescence. Personality and Individual Differences 19: 333-338.
30. Mertz C, Brown J (2015) Confabulation: An Introduction for Psychologists. Forensic Scholars Today, 1: 1-2.

31. Fotopoulou A (2010) The affective neuropsychology of confabulation and delusion. Cogn Neuropsychiatry 15: 38-63. [Crossref]

32. Turner M, Coltheart M (2010) Confabulation and delusion: a common monitoring framework. Cogn Neuropsychiatry 15: 346-376. [Crossref]

33. Alderman N, Fry RK, Youngson HA (1995) Improvement of self-monitoring skills, reduction of behaviour disturbance and the dysexecutive syndrome: Comparison of response cost and a new programme of self-monitoring training. Neuropsychological Rehabilitation 5: 193-221.

34. Huntley D, Brown J (2016) Understanding confabulation: An introduction for crimina justice and mental health professionals. Forensic Scholars Today 1: 1-4.

35. Fotopoulou A, Conway MA, Solms M (2007) Confabulation: Motivated reality monitoring. Neuropsychologia 45: 2180-2190.

36. Kopelman MD (2010) Varieties of confabulation and delusion. Cogn Neuropsychiatry 15: 14-37. [Crossref]

37. Hanba JM, Zaragoza MS (2007) Interviewer feedback in repeated interviews involving forced confabulation. Applied Cognitive Psychology 21: 433-455.

38. Zaragoza MS, Payment KE, Ackil JK, Drivdahl SB, Beck M (2001) Interviewing witnesses: Forced confabulation and confirmatory feedback increase false memories. Psychological Science 12: 473-477.

39. Turner MS, Cipolotti L, Yousry TA, Shallice T (2008) Confabulation: Damage to a specific inferior medial prefrontal system. Cortex 44: 637-648.

40. Dalla Barba G, Boisse MF (2010) Temporal consciousness and confabulation: Is medial temporal lobe "temporal"? Cognitive Neuropsychiatry 15: 95-117.

41. Demery JA, Hanlon RE, Bauer RM (2001) Profound amnesia and confabulation following traumatic brain injury. Neurocase 7: 295-302.

42. Johnson MK, Hayes SM, D’Esposito M, Raye C (2000) Confabulation. In: Boller F, Grafman J (Eds.), Handbook of neuropsychology: Memory and its disorders (2nd edn., Vol. 2, pp. 383-407) Amsterdam, The Netherlands: Elsevier Science.

43. Salazar-Fraile J, Tabarés-Seisdedos R, Selva-Vera G, Balanzá-Martinez V, Marti'nezArn A, et al. (2004) Recall and recognition confabulation in psychotic and bipolar disorders: Evidence for two different types without unitary mechanisms. Comprehensive Psychiatry 45: 281-288.

Copyright: (C2017 Brown J. This is an open-access article distributed under the terms of the Creative Commons Attribution License, which permits unrestricted use, distribution, and reproduction in any medium, provided the original author and source are credited. 